\title{
SCOPING STUDIES FOR SMALL STEADY-STATE TOKAMAKS FOR DIVERTOR TESTING*
}

\author{
J. D. Galambos, Y.-K. M. Peng, B. E. Nelson. S. P. Hirshman, and P. J. Fogarty \\ Post Office Box 2009 \\ Oak Ridge, TN 37831-8218
}

Abstract

Table 3 lists the variables (and their bounds) which were allowed to

A prime uncertainty in next-generation devices is the divertor performance. For the International Thermonuclear Experimental Reactor (TTER), the divertor limit often plays a more critical role in the operational scenario definition than do bets limit and energy confinement constraints. Hence. it is desirable to test the divertors in an environment as close as possible to that expected in next-step buming plasma experiments. Initial global scoping studies are done for small, steady-state, copper coil. beam-driven tokamaks that are dedicated to divertor testing. The usual ITER global physics models (bets limit, energy confinement, and analytic divertor heat load calculation) are incorporated, and for performance criteria we require that the divertor heat load and plasma collisionality in the edge region be similar to those expected in ITER. The smallest. lowest-cost devices satisfying these constraints tend to have major radius below $1 \mathrm{~m}$. plasma current of $0.5 \mathrm{tc} 1 \mathrm{MA}$, and low aspect ratio and costs of a few tens of mullions of dollars. Injection powers of about 4 to $5 \mathrm{MW}$ are needed to sustain the plasma current, maintain plasma power balance. arid provide the required divertor heat load.

\section{Objective}

Divertor operation is expected to be a primary obstacle in the operation of a near-ignited cokamak. I To further compound the problem. at this time predictions for the divertor conditions of these devices are very uncertain. A test bed for divertor operation, under conditions as close as possible to those expected in high-Q tokamat: operation, would be highly desirable. To this end, we search for small, low-cost tokamaks, that would be dedicated solely to the purpose of divertor testing. The only mission requirements for this device are to provide divertor conditions as close as possible to those expected in ITER. To find the "bare-bones" minimum cost, we take credit for existing site facilities located at Oak Ridge National Laboratory (these are mostly power supplies and injection power equipment), although similar results could result for other sites. We formulate the problem in the following section and identify minimum cost solutions in Section III. Minimum cost devices in the aspect ratio range of 1.5 to 3 have major radii ranging from roughly 0.5 to $1.0 \mathrm{~m}$ and costs in the tens of millions of dollars.

\section{Method}

The present analysis uses a simple systems code. In particular, the cost algorithms and magnet models are kept simple for expediency, but they should be adequate for this initial scoping task. The constrained optimization procedure incorporated in other systems codes (TETRA ${ }^{2}$ ) are used here. The analysis is done with a version of the $S T A R^{3}$ code. Generally, the global ITER modeling rules ${ }^{4}$ are used with the exception of plasma current, poloidal fields, and plasma volume calculations, which are modified to apply at low aspect ratio $(A<2)$.

\section{II.1 Assumptions}

Many of the configurational/operational scenario assumptions are described in Table 1 . These are generally fixed input values. An important assumption used here is the absence of an inductive solenoid. Since the device is to be steady-state, noninductive current drive means will be needed.

\section{2 Constraints}

We imposed a set of constraints that are described in Table 2. The pnmary "perfornance" constraints are that the divertor hear load must be between 5 and $10 \mathrm{MW} / \mathrm{m}^{2}$ and that the scope-off plasma be collisional. The plasma power balance, beta limit, and density limit use the scalings imposed for ITER studies. The magnets are constrained by current density limits ( see also Tables 3 and 4 ).
11.3 Free parameters

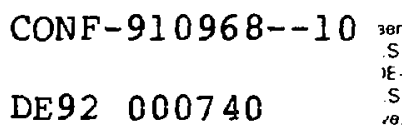

the published torm of thus contribution or allow others to do so. for US Government purpases

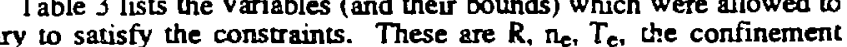
$H$-factor, $q, B_{1}, P_{\text {heat. }}$. The aspect ratio, while not listed in Table 3, is varied parametrically.

\section{4 Solution Method}

In the solution process, we optimize for minimum cost. The costing method is outlined in Table 4 using the unit costs based on the ATF experience. 5 Note that all costs here are in 1987 dollars (it is estimated that the cost escalation factor at ORNL to 1991 dollars is about 1.75). Also note that credits are taken in the injection power cost category. The solution method is to find the minimum cost device inat uses the assumptions listed in Table 1 , satisfies the constraints in Table 2, and allows the quantities listed in Table 3 to vary. More description of the modeling used here is given in the following section.

\subsection{Description of Models}

Divertor Madel. The analytic Harrison/Kukushkin model developed in the TER studiest is used here. A key assumption used in this application is $n_{\text {separarix }} / n_{e}=0.333$, which is similar $w$ that used in the ITER sudies. Higher density ratios would alleviate the diverior collisionality and heal load limits. We scale the divertor connection lengths with the edge $q$ and $R$, appropriately fitted to match the ITER results. Also, the poloidal distance from the $x$-point to the strike point is taken to be the minimum ( $0.5 \mathrm{~m}, 2 \times$ rplasma $_{\text {p }}$ as compared to $1.5 \mathrm{~m}$ for ITER. We choose a relatively long distance (compared ic the plasma size) here to allow ample room in the divertor chamber to accommodate divertor variations and diagnostics. The heat load is limited to a range $\left[5 \leq \mathrm{H}_{\text {div }}\left(\mathrm{MW} / \mathrm{m}^{2}\right) \leq 10\right]$ which is in the neighborhood of that expected in ITER before applying safery margins. We choose a range ralher than a single vahue for $\mathrm{H}_{\text {diy }}$ so that this constraint is not too restrictive on the device parameters. It is expected that this device will have some control on the heat load by varying the flux expansion near the strike point [by use of poloidal field (PF) coils close to the diveror].

Physics. The physics modeling generally follows that outlined in the ITER physics document. 4 The notable exceptions are in the plasma current scaling with field and plasma size/shape-for which we use the methods developed by $M$. Peng. ${ }^{6}$ which is valid at low and high aspect ratios. These methods from Ref. 6 are also used to find the poloidal field and plasma volume. An important modeling difference is for radiationwe assume $30 \%$ of the plasma heating power is radiated, for lack of a better low-temperaure line radiation/neutral charge-exchange power loss model. We assume an $\mathrm{H}$ plasma here, which affects some beam properties. Also, we have imposed a $60 \%$ upper bound to the bootstrap fraction, as many of the cases arrived at have very high poloidal betas, for which the ITER scalings predict bootstrap fractions $>60 \%$.

Current Drive. We note that no inductive capability constraint is used here. There is no central solenoid included in the radial build, and all the noninductively. Plasma startup is also assumed to be noninductive. In this sense. the cases presented with higher aspect ratio would be less affected if some inductive startup (or hybrid inductive/nonindustive long pulse) requirement were imposed. In this case a thin-wall vacuum vessel or a vacuum vessel with insulated breaks should be used. We assume neutral beam current drive and use the ITER model for current drive efficiency, not accounung for the possible acceleration of beam tons by the ICRF waves. The required beam energy for penetration is also calculared. assuming two e-fold decays to the plasma center. current (except for the bootstrap fraction) is assumed to be driven

\footnotetext{
Research sponsored by the Office of Fusion Energy, U.S. Department of Energy, under contract DE-AC05-84OR21400 with Martin Marietta Energy Systems. Inc.
}

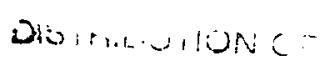

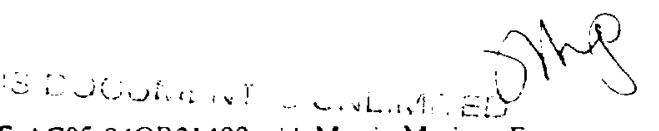

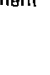




\section{DISCLAIMER}

This report was prepart as an account of work sponsored by an agency of the United States Government. Neit',er the United States Government nor any agency thereof, nor any of their employees. makes any warranty, express or implied, or assumes any legal liability or responsibility for the accuracy, completeness, or usefuiness of any information, apparatus, product, or process disclosed, or represents that its use would root infringe privately owned rights. Reference herein to any specific commercial product, process, or service by trade name, trademark, manufacturer, or otherwise does not necessarily constitute or imply its endorsement, recommendation, or favoring by the United States Government or any agency thereof. The views and opinions of authors expressed herein do not necessarily state or reflect those of the United States Government or any agency thereof. 
Poloidal Eield Coils. The PF coils are assumed to be internal. At this point no inductive current drive requirements are used. so no $\mathrm{OH}$ central solenoid is employed. The current density is assumed to be $10^{7} \mathrm{~A} / \mathrm{m}^{2}$. and the currents in the coils are taken from fits of the data in Ref. 6 :

$$
\begin{aligned}
& I_{\text {shaping coil }}=0.3 \times I_{\text {plasmas }} \times \mathrm{A} 1.6 \\
& I_{\text {vertical field coul }}=0.4 \times I_{\text {plosm }}
\end{aligned}
$$

(These fits are only good for A < 4). The data in Ref. 6 are for currents that produce a single equilibrium. Since flexibility of plasma shape, scrike pount flexibility, etc.. is likely to be needed in this experiment these scalings may underestimate the PF coil needs. On the other hand, since the PF coils are internal here (as opposed to extemal in Ref. 6), this should alleviate the PF coil requirements.

\section{Results}

We examined divertor testing tokamaks ranging from conventional aspect ratio $(A=3)$ down to Spherical Tokamak type aspect ratios ( $A$ near 1.5). Figure 1 shows minimum-cost device parameters over this range. The resulis can be sumnturizad as follows: (a) chere is a contunuous drop in device cost as the aspect ratio goes from 3 down to 1.6; and (b) the cost increases relatively steeply as $A$ is increased from 1.6 to 2.0. The drop in cost as A goes from 3 to 2 is due to the decrease in device size possible with lower aspect ratios (in this range the minimum mino: radius of $30 \mathrm{~cm}$ is met). Below $\mathrm{A}=2$, the plasma current begins to increase (because of the confinement and divertor collisionality consuaints), which tends to reduce cost beneñts of going to lower aspect ratos. Finally, below $A=1.6$ there is not enough room for the inner TF coll leg. and furcher decteases in $A$ cause a rapid increase in device size and cost.

Table 5 lists device parameters for $\mathrm{A}=1.6, \mathrm{~A}=2.0$, and $\mathrm{A}=3.0$ cases. The low-A cases are confinement limited $(H=2)$ but have some beta margin. whereas the higher-aspeci-ratio cases are beta limited but have some confinement margin assuming ITER power law scaling. The $\mathrm{H}$ facters required for plasma power balance for these cases show a wide spread, depending on the scaling used (we used the ITER Power scaling for these studies). Note that for ITER Offser Linear scaling, all examples in Table 5 would satisfy plasma power balance with "L-mode" continement (i.e.. $H \leq 1$ ). If lower densities are used for any of these coses, more confinement margin is obtained, at the sacrifice of the scrape-off layer SOL plasma collisionatity. Also, these cases have margin in the edge q. implying that higher plasma current could be possible if (a) the current drive efficiency were improved; (b) additional current drive power were available: (c) some inductive current drive "boost" were employed: and/or (d) lower SOL connection lengths were permitted. Higher cuirent could provide additional confinement or beta margin, but lowet edge $\mathrm{q}$ would reduce the SOL plasma collisionaity. Also, the beam energy nieded to penetrate to the plasma center for opumal current drive is $S 0 \mathrm{keV}$ for the lower-A cases, which allows utilization of existing beam equipment for current drive (1.5-MW crodit taken here).

Because of the lower $q-v a l u e s$, the higher-A cases are more strongly affected by the divertor collisionaity constraint than the low-A cases. $R e^{\prime}$ axing this constraint would allow lower toroidal field levels, and reduce the cost. Also. for the high-A cases the injection power is govemed by the need to mauntam a sufficient divertor heat load, tather than for plasma power balance. At low $A$, the siruation is reversed: the injection power requirements are dictated by the need to keep the $H$ facior $\leq 2$, and the resulung heat load is above the minimum 5-MW/ $\mathrm{m}^{2}$ level.

The total conl power requirements (for all cases in Table 5) range from -20 to $50 \mathrm{MW}$ as $\mathrm{A}$ increases from below $2 \mathrm{la} 3$. These power levels should be possible with upgrades to existing powet supplies. The lower-aspect-ratio example has lower cost primarily due to the lower magnet and injectuon power costs. Both of these lower costs are primarily due to the smaller device size and $R$. Note that we use a multitum inner TF coul leg-use of a single-urm "centerpost" concept un ocher applications may permit opumum points at lower $\mathrm{A}$.

\section{Summary}

Small divertor testing tokamaks to be used as a vehicle for providing a test bed for ITER-like divertor condilions have been invesugated at a prehminary systems code level. In parucular, we look at steady-state (no OH central solenoid) copper coil cases. which result in small $(0.5<\mathrm{R}(\mathrm{m})$ $<1$ ). surongly heated tokamaks that appear to have costs in the tens of millions of dollars (after site credits are taken). This appears to be an attractive route to producing high divenor heat loads in a tokamak contiguration-and wh a facility dedicated to divertor tesung.

\section{References}

[i] D. Baldwin et al.. "U.S. National Review of the ITER Conceptual Design Activity," Insutute for Fusion Studies, University of Texas. March 1991.

[2] TETRA svstems code: see R. L. Reid et al.. ETR/ITER Systems Code, ORNL/FEDC-877, 1988.

131 "STAR Code: Spherical Tokamak Aralysis and Reactor Code." Code manual is in preparation (this code was written for Culham for ST reactor sudies); see J. Galambos for copy of present document version.

[4] N. Uckan and the ITER Physics Group, "ITER Physics Guidelines," ITER-TN-PH-0-5. Nov. 1990.

[5] B. Nelson private communication, 1991.

(6) Y..K. M. Peng and D. J. Strickler, "Features of Spherical Torus Plasmas." Nucl. Fusion 26, 769 (1986).

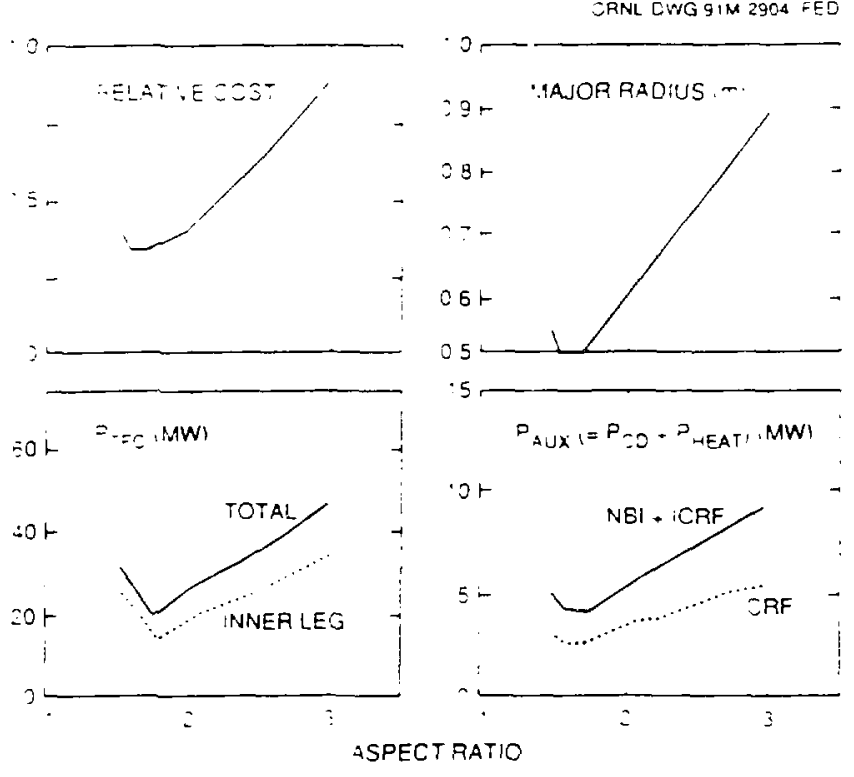

Fig. 1. Aspect ratio of a small steady-state divenor-technology tokamak vs (a) relative minimum cost. (b) major radius, (c) total TF coil resistive power and that from the irmer leg, and (d) total injection power (NB + lCRF) and that porion used only for heaung (ICRF). 


\section{Comment}

Irternal PF coils

Gap (first wall / inner TFC leg) $=1 \mathrm{~cm}$

First wall thickness - midplane $=6 \mathrm{~mm}$

Scrape-off thickness - midplane $=3 \mathrm{~cm}$ Gap (First wall/outer TFC leg) $\geq 25 \mathrm{~cm}$ $\kappa_{\mathrm{K}}=2.05\left(1+0.44 \varepsilon^{2}\right)$

12 coils

All copper coils

OFHC copper for outer TF legs and PFC

Glidcop for inner TF legs if necessary
$\mathrm{NoOH}$ solenoid used

For coolant passages

ATF value

Same fraction of $\mathbf{r}_{\text {plasm }}$ as ITER

Allow room for vertical field coils

Fits ITER, higher elongation at lower A

Provides port size needed for beams

See a below

Use low $J$ and low unit costs b

May have higher unit costsb

The need for rapid changeout of diverwor test modules/components necessitates the need for demountable TF coils. which rules out the use of superconductors.

bSee Tables 3 and 4.

Table 2. Description of the global constraints used in this analysis

Constrainl

Comment

Overall consistency canstrainss

$I_{p}=I_{p}(A, R, q 95, K, \delta)$

Relates plasma current to field and geomery

$B_{o} R=B_{\max } R_{\text {tf }}$ Relates the field at the coil wo field on axis

$\Sigma$ inboard radial thickresses $=R$ Inboard radial buildup $=$ major radius

Plasma power balancea

$\beta \leq$ limit

$n_{e} \leq$ disnuption density limit

Plama constraints

See below

Troyon scaling with $\mathrm{g}=3 \mathrm{~m}-\mathrm{T} / \mathrm{MA}$

Using the Borass (TTER) model with a

coefficient corresponding to $\mathrm{H}$-mode

confinemerit

edge $q \geq 3\left(1+2.6 \varepsilon^{2.8}\right)$

Limit is $=3$ for $A>2 \mathrm{~m}$ higher al lower $A$

$5<\mathrm{H}_{\text {div }}\left(\mathrm{MW} / \mathrm{m}^{2}\right)<10$

Divertor hear loade

$\lambda_{\text {ic }}<$ divertor comection length $b$

[ivertor plasma is collisiona]

Plasma minor radius $\geq 30 \mathrm{~cm}^{c}$

Configuration constrains

See below

Por size $(0.3 \mathrm{~m})$ for tangential beam

injection outboard field nipple $\leq 1.0 \%$

Rough linut for available power supplies

Positions outer legs

The terms included are injection power, radiation (set to be $30 \%$ of injection power). and transpon power. We let the confinement $H$-factor vary (subject to $H \leq 2$ ) for the ITER power-law and offset-linear scaling expressions.

bSee Section II.5.

This constraint plays an important role in the device size/cost. It is important to ensure that the plasma transport is not dominated by atomic effects and to provide an adequate turget for neutral beam injection.

The line power available at ORNL is over $100 \mathrm{MVA}$, which is greater than would be needed here. The $60-\mathrm{MW}$ limit is indicative of the power supplies available (from ATF magnes) that may be modified for steady-state use hete.

e See the divertor model description in the Appendix and Section $\Pi$. 
Table 3. Quantities allowed to vary in the device selection process

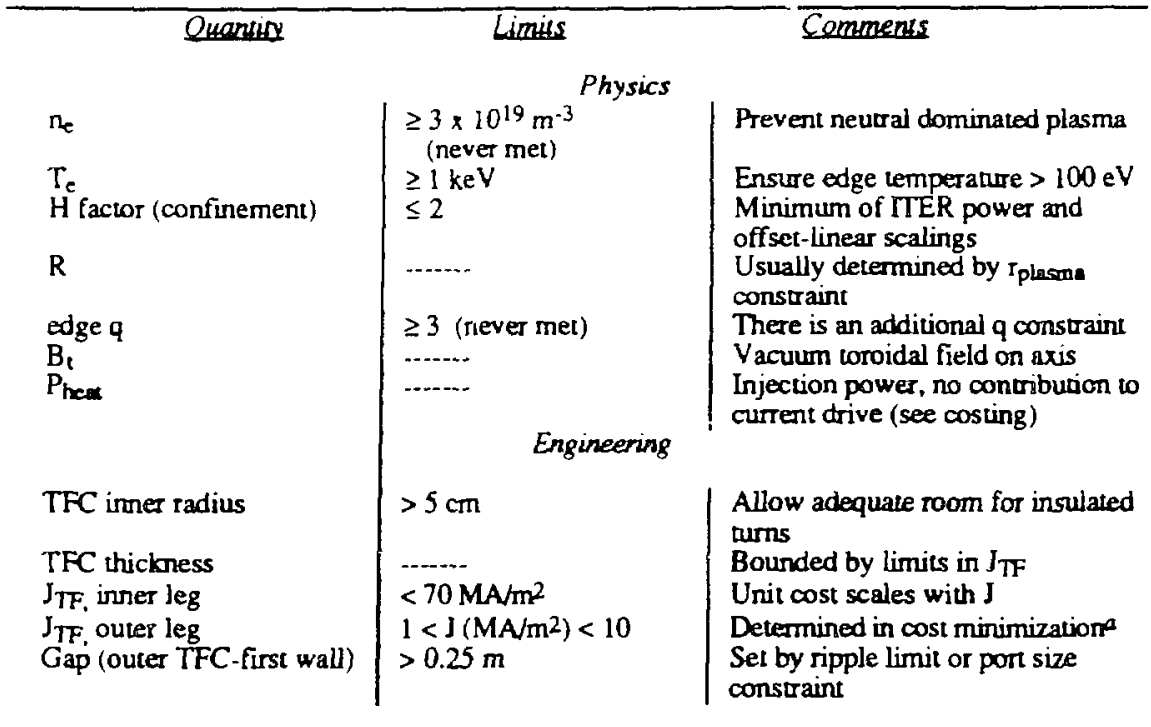

The upper bound of $10 \mathrm{MA} / \mathrm{m}^{2}$ is used to be consistent with the lower unit cost of the outer TF coil legs.

Table 4. Cost method used in the device selection process. Costs are in 1987 S. It is estimated that woday's costs (ar ORNL) include an escalation factor of about 1.75

\begin{tabular}{|c|c|}
\hline Categar & Commen \\
\hline TE Coils & \\
\hline $\begin{array}{l}\text { Inner coils }= \\
250 \$ / \mathrm{kg} \text { when } \mathrm{J} \leq 30 \mathrm{MA} / \mathrm{m}^{2} \\
250 \mathrm{~S} / \mathrm{kg} \times\left[\mathrm{J}\left(\mathrm{MA} / \mathrm{m}^{2}\right)+10\right] / 40 \\
\text { when } \mathrm{J}>30 \mathrm{MA} / \mathrm{m}^{2}\end{array}$ & ATF HF coils $=250 \$ / \mathrm{kg}$ \\
\hline Outer $=1505 / \mathrm{kg}$ & \\
\hline $150 \$ / \mathbf{k g}$ & ATF PF coils $=150 \$ / \mathrm{kg}$ \\
\hline $10^{\frac{\text { Vacumm vessel }}{5 / \mathrm{m}^{2}}}$ & May be too high, from ITER scalings \\
\hline $\begin{array}{l}\text { Support structure } \\
190 \mathrm{~S} / \mathrm{kg}\end{array}$ & $A T F=190 \$ / k g$ \\
\hline Iniection oower & \\
\hline Current drive $=\$ \$ / W_{\text {plasme }}$ & First $1.5 \mathrm{MW}$ is free (credit for existing aquipment \\
\hline $\begin{array}{l}\text { Healing only power }=3 \$ \mathrm{~W} \text { plasme } \\
\text { Coolinesustem }\end{array}$ & First $2 \mathrm{MW}$ is free (credit for existing equipment) \\
\hline $1.4 \times 10^{4} 5 \mathrm{MWW}$ & $\begin{array}{l}\text { From ATF. This may increase if } \\
\text { the cooling tower capability is exceeded }\end{array}$ \\
\hline $300 \frac{\text { Divertor cests }}{\mathrm{S} / \mathrm{kg}}$ & Not included in ATF, but important here \\
\hline $2.2 \mathrm{M} \$$ & From ATF \\
\hline
\end{tabular}

a Support mass is taken to be $0.34 \times$ (TFC + PFC mass), which is also taken from ATF.

$b$ Divertor costed as two (top/bottom) 25 -cm-thick disks extending from the outer plasma edge to the inner edge.

cAccounts for assembly equipment, design integration, site preparation. and electrical and instrumentation systems. 
Table 5. Parameters for minimum cost $A=1.60 . A=2.0$ and $A=3.0$ cases.

\begin{tabular}{|c|c|c|c|}
\hline & A: 1.60 & $\mathrm{~A}=2.0$ & $\mathrm{~A}=3.0$ \\
\hline \multicolumn{4}{|l|}{ Phusics parameters } \\
\hline 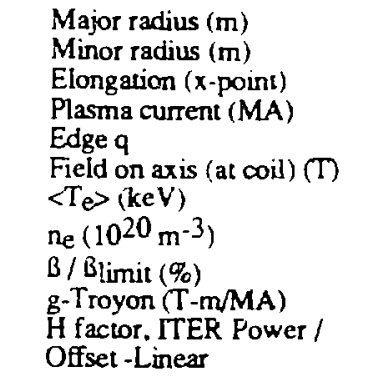 & $\begin{array}{l}0.48 \\
0.30 * \\
2.40 \\
0.62 \\
18.0 \\
1.4(5.1) \\
1.0 * \\
0.69 \\
4.0 / 4.4 \\
2.8 \\
2.0 * / 0.90\end{array}$ & $\begin{array}{l}0.60 \\
0.30^{*} \\
2.26 \\
0.55 \\
12.0 \\
1.7(4.1) \\
1.1 \\
0.70 \\
3.2 / 3.2 * \\
3.0^{*} \\
2.0^{*} / 0.95\end{array}$ & $\begin{array}{l}0.90 \\
0.30^{\star} \\
2.14 \\
0.56 \\
6.5 \\
2.2(3.5) \\
1.0^{\star} \\
0.81 \\
2.6 / 2.6^{*} \\
3.0^{\star} \\
1.4 / 0.75\end{array}$ \\
\hline \multicolumn{4}{|l|}{ Divertor porameters } \\
\hline $\begin{array}{l}\text { Hear load }\left(M W / m^{2}\right) \\
\lambda_{\text {ie } / \text { connection length }}\end{array}$ & $\begin{array}{l}8.2 \\
1.0^{*}\end{array}$ & $\begin{array}{l}5.0^{*} \\
1.0^{*}\end{array}$ & $\begin{array}{l}5.0^{*} \\
1.0^{*}\end{array}$ \\
\hline \multicolumn{4}{|l|}{ Injection power } \\
\hline $\begin{array}{l}\text { Current drive power (MW) } \\
\text { Heating power (a) } \\
\text { Bootstrap fraction } \\
\text { Beam energy (keV) } \\
\text { Drive efficiency }\left(\mathrm{A} / \mathrm{W}-\mathrm{m}^{2} \text { ) }\right.\end{array}$ & $\begin{array}{l}3.1 \\
1.2 \\
0.60^{*} \\
40 \\
0.026\end{array}$ & $\begin{array}{l}3.3 \\
2.0 \\
0.60 \\
50 \\
0.028\end{array}$ & $\begin{array}{l}7.2 \\
2.0 \\
0.55 \\
90 \\
0.025\end{array}$ \\
\hline
\end{tabular}

At a limit.

This power only heats the plasma and does not contribute toward current drive (i.e., ICRH power). Note that $2 \mathrm{MW}$ of this power is assumed to be available "free."

Table 5 (continued). Device parameters for the $A=1.6, A=2.0$ and $A=3.0$ cases

\begin{tabular}{|c|c|c|c|}
\hline Inboard TF coil lees & $A=1.60$ & $A=2.0$ & $A=3.0$ \\
\hline $\begin{array}{l}\left.\text { Current censity (MA/m }{ }^{2}\right) \\
\text { Mass (1000 kg) } \\
\text { Resistive power (MW) }\end{array}$ & $\begin{array}{l}70^{*} \\
0.9 \\
23\end{array}$ & $\begin{array}{l}43 \\
2.1 \\
20\end{array}$ & $\begin{array}{l}42 \\
3.8 \\
35\end{array}$ \\
\hline $\begin{array}{l}\text { Qufbogrd TE legs } \\
\text { Current density (MA/m²) } \\
\text { Mass (10.J0 kg) } \\
\text { Resistuve power (MW) }\end{array}$ & $\begin{array}{l}10^{*} \\
12 \\
4.3\end{array}$ & $\begin{array}{l}10^{*} \\
18 \\
6.4\end{array}$ & $\begin{array}{l}10^{*} \\
35 \\
12.2\end{array}$ \\
\hline
\end{tabular}

\section{Cost breakdown (1987 M 1}

\begin{tabular}{ll|l|l} 
Inner TF coil legs & 0.4 & 0.7 & 1.2 \\
Orter TF coil legs & 1.8 & 2.8 & 5.2 \\
PI: coils & 0.6 & 0.7 & 1.4 \\
Vacuum vessel & 0.3 & 0.4 & 0.6 \\
Ciurent drive & 4.8 & 5.3 & 17.4 \\
Ifeating power. & 0 & 0 & 0 \\
Support structure & 1.1 & 1.6 & 3.1 \\
Cooling & 0.4 & 0.4 & 0.7 \\
Divertor & 1.9 & 2.4 & 3.6 \\
Fixed & 2.2 & 2.2 & 2.2 \\
Total & 13.6 & 16.5 & 35.4
\end{tabular}

"Cost credit is taken for $2 \mathrm{MW}$.

This is the power used only for heating and does not cor:tribute loward current drive. 